\title{
All that Glitters is not Gold: Six Steps before Selecting and Prioritizing e-Health Services
}

\author{
Tobias Mettler ${ }^{1}$ and Vivian Vimarlund ${ }^{2}$ \\ ${ }^{1}$ Swiss Graduate School of Public Administration, University of Lausanne, Rue de la mouline 28, \\ 1022 Chavannes-près-Renens, Switzerland. E-mail: tobias.mettler@,unil.ch, phone: +41 21692 \\ 6950 \\ ${ }^{2}$ Department of Computer and Information Science, Linköping University, Ingång 29C Campus \\ Valla, 58183 Linköping, Sweden. E-mail: vivian.vimarlund@,liu.se
}

Citation: Mettler T, Vimarlund V. All that glitters is not gold: Six steps before selecting and prioritizing e-health services. Journal of Medical Systems; https://doi.org/10.1007/s10916-0170801-9

\begin{abstract}
Since the market for e-health applications is constantly growing, it is getting an ever more complex endeavor to select and prioritize the right service offering given a particular situation. In examining the extant literature, it was revealed that little emphasis is actually placed on how to analyze contextual or environmental factors prior to the selection and prioritization of e-health services. With this paper, we therefore propose a formative framework consisting of six fundamental yet very pragmatic steps that may support decision makers in identifying the most important contextual pre-requisites that e-health services need to fulfill in order to be considered as effective for their environment to be implemented.
\end{abstract}

\section{KEYWORDS}

E-health, information technology, procurement, service evaluation 


\section{INTRODUCTION}

Several studies have shown that the successful implementation of e-health services within and across healthcare organizations not only requires the integration of processes, work practices $[1,2]$, and timely and role-specific exchange of information and education $[3,4]$, but also in most cases effective personal interaction between the different actors involved [5-7]. This means that prior to deciding about the procurement or development of a new e-health service, the degree of integration between technology and organization, as well as the identification of obstacles and opportunities needs to be analyzed. Hence in order to do so, a profound evaluation of the potential positive and negative effects of a new service should be conducted upfront [8]. However, evaluators of e-health services frequently are faced with time, budget or personnel restrictions as well as with a lack of a formative framework for decision-making [9]. On the contrary, the findings emerging from such an evaluation must be as accurate and unequivocal as possible, so that the utility of the evaluated object is clearly understood by both the payers and users of the new e-health service.

\section{BACKGROUND AND SIGNIFICANCE}

In the existing literature, particularly in the areas of computer science $[10,11]$ and management science [12-14], several approaches, ranging from primitive to extremely sophisticated techniques, are suggested to select and prioritize IT-reliant and non-automated services (see table 1). Heuristics typically represent the simplest form of selection techniques for prioritizing different services. It is particularly useful, where no optimal solution exists or where finding the solution is too expensive or even computationally intractable. However, it is less suitable for contradictory or conflicting situations, especially when different stakeholders are being asked. In the area of e-health it has especially been applied for evaluating the compliance of services according to recognized usability principles [15-17]. 
Policy-based selection techniques are similar to heuristics, however, instead of defining simple rules of thumb, cohesive selection standards, guidelines or policies are specified [18]. By equally considering the preferences and limitations of different roles (e.g. payers of services, users of services), the resulting decision is quite likely to reach a general consensus. Still the policy needs to be translated into something 'practical' such as an assessment questionnaire, which is often a complex and error-prone endeavor and even might be fueled by organized interests and media attention [19].

Another kind of service selection is multi-criteria decision analysis, which qualifies for numerous and possibly conflicting evaluations. Multi-criteria decision analysis methods are particularly well suited for complex service selection, for which several criteria need to be judged [20]. Multicriteria decision analysis methods include Analytic Hierarchy Process (AHP) and its successor Analytic Network Process (ANP), goal programming, and weighted product or sum models $[21,22]$. Albeit the analytical potential of such approaches, it has been shown that it is often too complex and time-consuming for practice.

A different strategy is taken by reputation or trust-based selection techniques. While prior approaches base their decision on self-judgment, reputation and trust-based techniques rather rely on the recommendation of a third-party. Surely, this might be an interesting approach to follow in order to democratize the selection of e-health services [23], however, it is of major concern since several studies reported misuse and manipulation on commercial platforms (e.g. Amazon, eBay). Moreover, it is quite a lengthy process to build up a representative community of trust. 
Table 1 Overview of common service selection techniques as reported in the computer science and management science literature

\begin{tabular}{lll}
\hline SELECTION TECHNIQUE & ADVANTAGE & DISADVANTAGE \\
\hline Heuristics & Fast and cheap service selection & $\begin{array}{l}\text { Less suitable for contradictory } \\
\text { or conflicting situations }\end{array}$ \\
Policy-based & $\begin{array}{l}\text { Considers preferences and } \\
\text { limitations }\end{array}$ & $\begin{array}{l}\text { Specification of policies is } \\
\text { complex and time-consuming }\end{array}$ \\
$\begin{array}{l}\text { Accommodation of multiple } \\
\text { analysis }\end{array}$ & $\begin{array}{l}\text { Lengthy duration of the process } \\
\text { criteria, facilitation of } \\
\text { participation, simple and } \\
\text { intuitive character }\end{array}$ & $\begin{array}{l}\text { number of criteria } \\
\text { numbion }\end{array}$ \\
$\begin{array}{l}\text { Reputation-/ } \\
\text { trust-based }\end{array}$ & $\begin{array}{l}\text { Decision is based on own and } \\
\text { others' experiences }\end{array}$ & $\begin{array}{l}\text { reputation- and trust community } \\
\text { / potential of manipulation of } \\
\text { evaluations }\end{array}$ \\
\hline
\end{tabular}

The previous assessment of the literature was an appropriate and necessary step to understand the benefits and downfalls of the different current service selection techniques. In particular it was found that an overall formative framework is missing that somehow guides the procedure of selecting and prioritizing a service. Moreover, the literature analysis also revealed that little emphasis was given to analyzing contextual or environmental factors when selecting a service $[24,25]$. As a consequence, we propose a formative framework that supports decision makers in identifying the most important contextual pre-requisites that e-health services (ex ante) need to fulfill in order to be considered 'effective' or 'useful' for the environment they are supposed to be integrated in.

\section{METHODS}

Building upon empirical evidence from previous qualitative research, we developed a theoretical model containing the main contextual influencing factors of e-health services deployment. We validated our assumptions specified in the model through interviewing nine key stakeholders from the County Council at Stockholm (CCS), Sweden. The respondents were purposively selected and included project leaders for different e-health initiatives at CCS, e-health strategists 
and persons working with procurement of healthcare services. Common to all was that they were involved in the process of ordering, replacing and monitoring (IT-reliant and non-automated) health services, and are thereby involved in the task of ordering and identifying potentially favorable new e-health services.

By means of semi-structured interviews, the selected individuals were asked to report on their visions regarding the innovation effects the introduction of e-health services have to bring to healthcare, as well as their expectations about the economic effects this kind of services where expected to contribute to. The documented results of the interviews and observations served as basis for refining as well as adjusting the theoretical model to the 'reality of practice'.

\section{RESULTS}

The final version of the formative framework is summarized in figure 1. It consists of six basic steps that address various aspects before selecting and prioritizing the procurement or development of a new e-health service: (1) identification and sorting of goals and potential effects, (2) determination of organizational requirements, needs and preconditions, (3) evaluation of costs for building/acquiring and maintaining the service, (4) definition of measures to shorten the time between service introduction and sustainable usage, (5) identification of rewards and incentives for involved actors, and (6) development of a comprehensive picture of the e-health service implementation. 


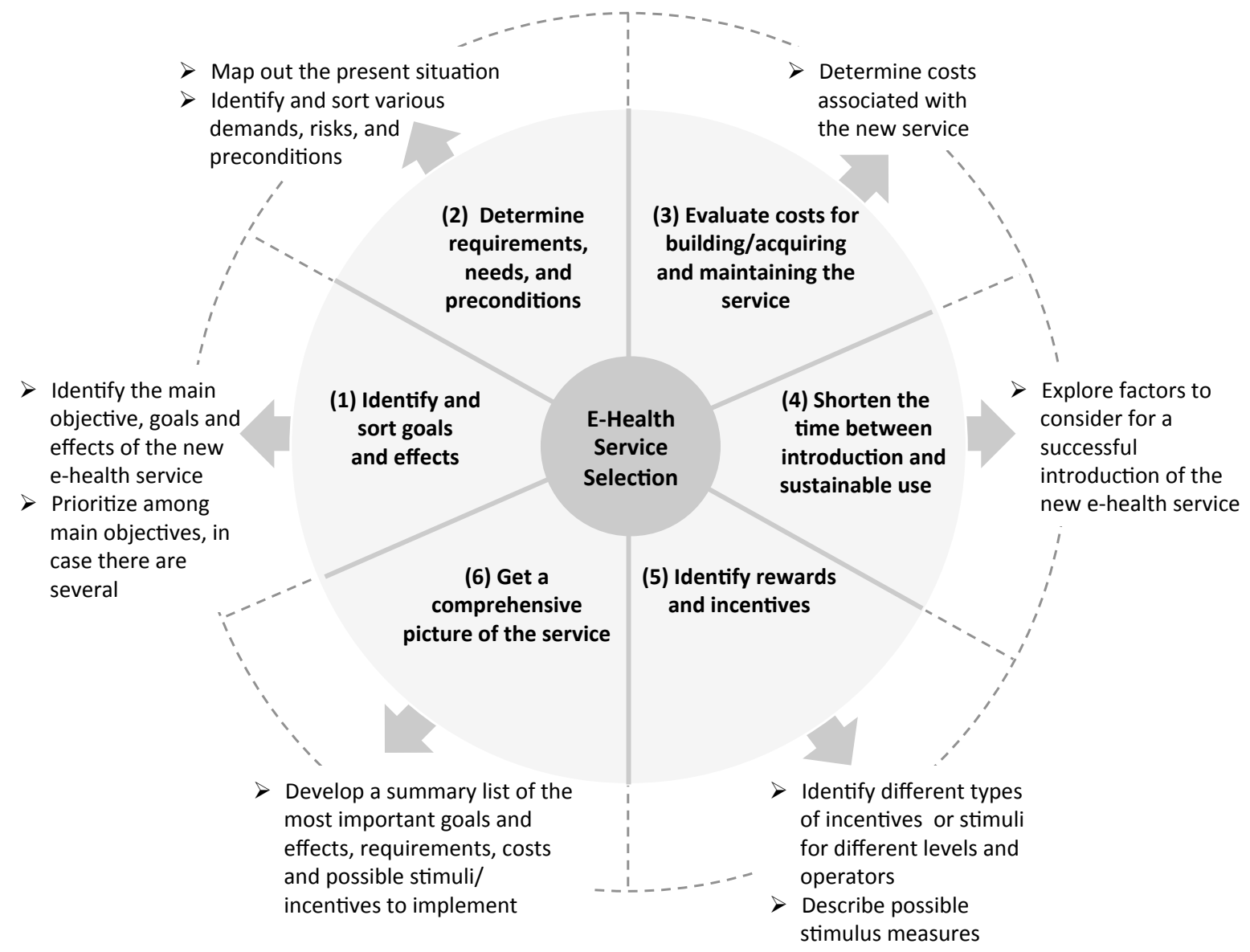

Figure 1 Proposition of steps to be followed before selecting and prioritizing e-health services

\section{Step 1: Think about why a new e-health service is required}

Before thinking of developing or acquiring a new e-health service (what?) and thinking of its implementation (how?), it is a crucial first step to fully understand the purpose and goals (why?) that should be fulfilled. Typically, these are multiple objectives that sometimes are contradictive or differ in levels of importance (e.g. "must have" and "nice to have"). This builds the basis for the subsequent prioritization and decision-making process.

Step 2: Determine the needs and preconditions of the actors involved

When the goals are clear why a new e-health service is needed, it is an important second step to reflect on technical, operational and economic conditions that must be fulfilled either by the technology provider or by the organization in which the service will be implemented in order to avoid the risk of missing potential positive effects. In addition, also the most important 
requirements and needs of possible service consumers or 'end-users' (e.g. patients, relatives, family doctors etc.) have to be thoroughly explored and systematically collected.

Step 3: Estimate direct and indirect costs of the potential new service

In a third step, decision makers should try to make approximations with respect to the costs associated with building or acquiring and maintaining the e-health service for the next couple of years. The estimation of costs should not only consider direct, technology-based expenses. There should be also emphasis on, for instance, (i) adjustment costs related to individuals' willingness (or unwillingness) to accept the new e-health service (ii) transition costs that come with the parallel provision of the old and new service for a certain amount of time, and (iii) costs that may arise as a result of inexperienced users, or as a consequence of the user to feel uncertainty and unfamiliarity when a new routine or work practice is introduced.

\section{Step 4: Think of measures to shorten the time between introduction and sustainable use}

Research in the field of diffusion and adoption of technology revealed that it is difficult to avoid the so called 'productivity paradox' [26], i.e. that productivity does not increase just as a consequence of implementing a new solution. Part of this effect is due to the fact that with the introduction of a new e-health service always goes along with a relatively big change in behavior and skills for both producer and consumer the service. Hence, strategies and measures have to be formulated in order to shorten the time between the introduction and the usage phase (the subsequent rewards and incentives is just one possible aspect though).

\section{Step 5: Formulate incentives and rewards}

After identifying the major financial and organizational effects that come with the implementation of a new e-health service, in a fifth step it should be discussed what kind of incentives or encouragements have to be given to the different involved actors so that acceptance is increased (or resistance is diminished) and the intended usage is followed. Since evidence exists that with the introduction of a new e-health service there is often a demand for ceding or replacing old habits by novel work practices, some measures have to be initiated to 
guarantee that this change actually happens. What initially seemed to be a safe investment in IT with clear effects on savings and profit growth may in practice prove to end up somewhere else. Therefore, it is of utmost importance to get management attention and support for communicating the 'social utility' of the new service as well as actively leading the transition from vision to operationalization.

\section{Step 6: Draft an overall big picture}

In order to making the results of the previous steps broadly communicable, an overall big picture' of the goals and effects, organizational, technical and economic requirements, costs to consider, and different needs in order to shorten the time between implementation and full use of the new service in order to be able to make a better assessment or monitoring should be drafted in the final step.

\section{Discussion AND ConClusion}

A common error when discussing how to select e-health services is to think that it automatically contributes to effectiveness and efficacy increases and to simplifications of administrative and medical processes. A new e-health service, however, is not able to replace high skill levels in a healthcare organization. On the contrary, its aim must be to enable the creation of new opportunities for communication and interaction between healthcare providers and between patients. In some cases, this will mean that an organization can grow and expand, in other cases the opposite effect occurs. Part of the difficulty of selecting or developing a sustainable service, is the limited ability to predict the future as well as the lack of current selection techniques to sufficiently consider contextual factors that might influence the acceptance and adoption behavior of the service.

In this paper, we therefore tried to discuss the 'fundamentals' a healthcare organization needs to reflect on before actually getting in contact with technology. After reviewing the extant literature, we found that an overall formative framework is missing that guides or advises decision-makers 
during the complex task of selecting a particular e-health service. The six basic steps of the proposed formative framework are thus supposed to be a kind of thought pattern for decision makers who are in charge of promoting the broader adoption of e-health. In doing so, we predefined some of the critical questions and practical challenges, such as identifying and sorting of goals and potential effects before thinking of a concrete technology, reviewing organizational requirements and preconditions for the adoption of a solution, or thinking about how to finance a new e-health service and account for the "value-for-tax-money" in advance.

Our formative framework intends to be a memento or help for decision-making. The responsibility of correctly determining the relevance of goals, effects, and requirements associated with e-health services, to prioritize them and to relate them to the visions and strategic goals of the specific health organization or system remains a core responsibility of public managers and policy analysts. While such decisions cannot be fully automatized or outsourced, there is a lot of potential in widening the use of predictive algorithms in government decisionmaking. Although this has not been a focus of this article, it could represent a new and exciting avenue for future research particularly as it not only presents technical challenges but also requires a thoughtful ethical and legal debate. Moreover, it is important to mention that service selection and prioritization is but the first step to achieve a holistic impact assessment of e-health services. Additional research is needed to link other assessment approaches, such as for example for service operations, quality, and innovation $[27,28]$, in order to gather insightful information about an e-health service along the entire service lifecycle.

\section{ACKNOWLEDGEMENT}

The authors would like to thank the Swedish eHealth Agency as well as the members of Stockholm County Council for their participation in this study. We also express our gratitude to the Swiss National Science Foundation for funding our research stay (grant no. IZK0Z1_142965). 


\section{REFERENCES}

1. Murray E, Burns J, May C, Finch T, O'Donnell C, Wallace P, Mair F (2011) Why is it Difficult to Implement E-Health Initiatives? A Qualitative Study. Implementation Science 6 (1):6

2. Staemmler M (2011) Service Delivery for E-Health Applications. Studies in Health Technology Informatics 169:537-541

3. Bygholm A, Günther J, Bertelsen P, Nøhr C (2012) eHealth Education of Professionals in the Baltic Sea Area. Studies in Health Technology Informatics 180:934-938

4. Mair FS, May C, O'Donnell C, Finch T, Sullivan F, Murray E (2012) Factors that Promote or Inhibit the Implementation of E-Health Systems: An Explanatory Systematic Review. Bulletin of the World Health Organization 90 (5):357-364

5. Mettler T, Rohner P (2009) An Analysis of the Factors Influencing Networkability in the Healthcare Sector. Health Services Management Research 22 (4):163-169

6. Ragaban N, Day K, Orr M (2012) Align, Share Responsibility and Collaborate: Potential Considerations to Aid in E-Health Policy Development. Studies in Health Technology Informatics $178: 186-191$

7. Berg M, Aarts J, van der Lei J (2003) ICT in Health Care: Sociotechnical Approaches. Methods of Information in Medicine 42 (4):297-301

8. Mettler T (2016) Anticipating mismatches of HIT investments: Developing a viability-fit model for ehealth services. International Journal of Medical Informatics 85 (1):104-115

9. Eslami Andargoli A, Scheepers H, Rajendran D, Sohal A (2017) Health information systems evaluation frameworks: A systematic review. International Journal of Medical Informatics 97:195-209.

10. D’Urso P, De Giovanni L, Spagnoletti P (2013) A fuzzy taxonomy for e-Health projects. International Journal of Machine Learning and Cybernetics 4 (5):487-504

11. Khoja S, Durrani H, Scott RE, Sajwani A, Piryani U (2012) Conceptual Framework for Development of Comprehensive e-Health Evaluation Tool. Telemedicine and e-Health 19 (1):48-53.

12. Li J, Ray P (2013) E-Health Readiness Assessment Methodology (EHRAM). In: Bali R, Troshani I, Goldberg S, Wickramasinghe N (eds) Pervasive Health Knowledge Management. Healthcare Delivery in the Information Age. Springer, New York, pp 331-349. 
13. Alalwany H, Alshawi S (2012) The rationale of e-health evaluation: the case of NHS Direct. International Journal of Business Information Systems 9 (4):484-497.

14. van Gemert-Pijnen JE, Nijland N, van Limburg M, Ossebaard HC, Kelders SM, Eysenbach G, Seydel ER (2011) A Holistic Framework to Improve the Uptake and Impact of eHealth Technologies. Journal of Medical Internet Research 13 (4):e111.

15. Kientz JA, Choe EK, Birch B, Maharaj R, Fonville A, Glasson C, Mundt J (2010) Heuristic Evaluation of Persuasive Health Technologies. Paper presented at the 1st ACM International Health Informatics Symposium, Arlington, USA,

16. Scandurra I, Hägglund M, Engström M, Koch S (2007) Heuristic Evaluation Performed by UsabilityEducated Clinicians: Education and Attitudes. Studies in Health Technology Informatics 130:205-216

17. Hundt AS, Adams JA, Carayon P (2017) A Collaborative Usability Evaluation (CUE) Model for Health IT Design and Implementation. International Journal of Human-Computer Interaction 33 (4):287-297.

18. Krupinski EA, Bernard J (2014) Standards and Guidelines in Telemedicine and Telehealth. Healthcare $2(1): 74-93$

19. Abelson J, Allin S, Grignon M, Pasic D, Walli-Attaei M (2017) Uncomfortable trade-offs: Canadian policy makers' perspectives on setting objectives for their health systems. Health Policy 121 (1):9-16.

20. McGee-Lennon M, Bouamrane M-M, Grieve E, O’Donnell CA, O’Connor S, Agbakoba R, Devlin AM, Barry S, Bikker A, Finch T (2017) A flexible toolkit for evaluating person-centred digital health and wellness at scale. In: Advances in Human Factors and Ergonomics in Healthcare. Springer, pp 105-118

21. Cancela J, Fico G, Arredondo Waldmeyer MT (2015) Using the Analytic Hierarchy Process (AHP) to understand the most important factors to design and evaluate a telehealth system for Parkinson's disease. BMC Medical Informatics and Decision Making 15 (Suppl 3):S7-S7

22. Sodhro AH, Shaikh FK, Pirbhulal S, Lodro MM, Shah MA (2017) Medical-QoS Based Telemedicine Service Selection Using Analytic Hierarchy Process. In: Khan SU, Zomaya AY, Abbas A (eds) Handbook of Large-Scale Distributed Computing in Smart Healthcare. Springer International Publishing, Cham, pp 589-609. 
23. Tursunbayeva A, Franco M, Pagliari C (2017) Use of social media for e-Government in the public health sector: A systematic review of published studies. Government Information Quarterly. Advance online publication. doi:http://dx.doi.org/10.1016/i.giq.2017.04.001

24. Boddy D, King G, Clark JS, Heaney D, Mair F (2009) The influence of context and process when implementing e-health. BMC Medical Informatics and Decision Making 9 (1):1-9

25. Troshani I, Wickramasinghe N (2016) An Organizing Vision Perspective for Developing and Adopting e-Health Solutions. In: Wickramasinghe N, Troshani I, Tan J (eds) Contemporary Consumer Health Informatics. Springer International Publishing, Cham, pp 271-281

26. Lapointe L, Mignerat M, Vedel I (2011) The IT productivity paradox in health: A stakeholder's perspective. International Journal of Medical Informatics 80 (2):102-115

27. Carvalho JV, Rocha Á, Abreu A (2016) Maturity Models of Healthcare Information Systems and Technologies: a Literature Review. Journal of Medical Systems 40 (6):131.

28. Hüsers J, Hübner U, Esdar M, Ammenwerth E, Hackl WO, Naumann L, Liebe JD (2017) Innovative Power of Health Care Organisations Affects IT Adoption: A bi-National Health IT Benchmark Comparing Austria and Germany. Journal of Medical Systems 41 (2):33. 